\title{
Clinical and scientific letters
}

\author{
Letters not directly related to articles published in Clinical \\ Medicine and presenting unpublished original data should be \\ submitted for publication in this section. Clinical and scientific \\ letters should not exceed $\mathbf{5 0 0}$ words and may include one \\ table and up to five references.
}

\section{Increased risk of ischaemic stroke while initiating warfarin in patients with atrial fibrillation}

A recent article revealed an increased risk of ischaemic stroke while initiating warfarin. ${ }^{1}$ We recently saw two such patients in their late seventies who suffered ischaemic strokes 4 and 5 days after initiation of warfarin. Their international normalised ratios (INRs) at the time of the stroke were 1.7 and 1.5 respectively, CT scans of the head were normal, neither received thrombolysis and there was no evidence of thrombus on their transthoracic echocardiograms.

During initiation of warfarin, there is a transient hypercoagulable state which could potentially increase the risk of ischaemic events. Until recently the risk was thought to be just theoretical. However a recent case control study showed an increased risk of stroke in the first 30 days of warfarin use (relative risk 1.71, 95\% confidence interval 1.39-2.12) with the highest risk in the first seven days. ${ }^{1}$ Also an increased risk of ischaemic stroke was seen in the two novel anticoagulant trials when patients were switched back to warfarin at the end of the study. ${ }^{2,3}$

The hypercoagulable state is due to earlier depletion of vitamin-K-dependent anticoagulant factors (proteins $\mathrm{C}$ and S) due to their shorter half-lives compared with the vitaminK-dependant clotting factors II, VII, IX and X. The half-life of inactivated protein $\mathrm{C}$ is 6.5 hours compared with $60-72$ hours of factor II. ${ }^{4,5}$ It is well known that individuals with protein C deficiency may suffer widespread thrombosis indicating that protein $\mathrm{C}$ is an important anticoagulant and regulator of the natural coagulation pathway.

Bridging therapy with heparin has always been part of clinical practice while initiating warfarin in venous and pulmonary thromboembolism. However there is no evidence for such practice in atrial fibrillation. It is debatable to suggest a change in practice based on few cases and retrospective study. However one should consider bridging therapy with heparin in high-risk patients, or the use of novel anticoagulants.

VEDAMURTHY ADHIYAMAN

KEIRAN O'MAHONY

Ysbyty Gwynedd, Bangor, UK

\section{References}

1 Azoulay L, Dell'Aniello S, Simon TA et al. Initiation of warfarin in patients with atrial fibrillation: early effects on ischaemic strokes. Eur Heart J 2014;35:1881-7.

2 Patel MR, Hellkamp A, Lokhnygina Y et al. Outcomes of discontinuing rivaroxaban compared with warfarin in patients with nonvalvular atrial fibrillation: analysis from the ROCKET AF Trial. J Am Coll Cardiol 2013;61:651-8.

3 Granger CB, Alexander JH, Hanna $\mathrm{M}$ et al. Events after discontinuation of randomized treatment at the end of the ARISTOTLE trial. Eur Heart J 2012;33(suppl 1):685-6.

4 Whitlon DS, Sadowski JA, Suttie JW. Mechanism of coumarin action: significance of vitamin $\mathrm{K}$ epoxide reductase inhibition. Biochemistry 1978;17:1371-7.

5 Bovil EG, Mann KG. Warfarin and the biochemistry of the vitamin K dependent proteins. Adv Exp Med Biol 1987;214:17-46.

\section{CARE - A risk-reduction acronym for clinical communications}

In British hospital practice the traditional 'firm' secretary has increasingly been replaced by a panoply of personnel, often responsible for supporting multiple clinicians and co-workers; typists, schedulers, support managers, workload co-ordinators and personal assistants all contribute to clinical pathways. Some units outsource some of these functions elsewhere within or outside the organisation, even overseas. The opportunity for miscommunication and administrative chaos is therefore great. A structured letter with the acronym 'CARE' is recommended to combat this risk and improve administrative efficiency.

CARE stands for copies, arrangements, results awaited, enclosures and is conveniently printed at the bottom of each letter

\section{Copies}

Patients should receive copies of every letter about them unless they would cause harm or distress, ${ }^{1}$ although it may then be appropriate to send them a copy of a letter with an 'addendum on all copies except the patient's'. This practice provides the patient with an aide memoire of their consultation. It also allows clinicians to write a single letter to multiple recipients, ensuring global appreciation of the clinical details. A structured letter makes it easier to navigate to relevant sections; a practice that will become common to all as standard communication headings are introduced across the UK health service. ${ }^{2}$

\section{Arrangements}

Investigations, operations, admissions and clinic appointments can be listed providing a single locus for schedulers to check. 
Where there are special arrangements appropriate details can be included.

\section{Results awaited}

Any investigations with outstanding results can be listed, preferably with an indication of when the result is likely to be available. A copy of the letter can be retained to ensure that the investigation result is sought if it fails to arrive timeously; a weekly 'results trawl' is recommended.

\section{Enclosures}

Investigation requests can accompany copies of the letter to departments providing diagnostic services facilitating more informed reporting. Information sheets can be sent to patients and GPs to educate them; this is a useful and efficient adjunct to informed consent.
'CARE' costs nothing, is simple and universally applicable. It is commended to support good medical care and as a riskreduction strategy.

$$
\begin{array}{r}
\text { SIMON R STUBINGTON } \\
\text { Michael Heal Department of Urology } \\
\text { Mid Cheshire Hospitals NHS Foundation Trust } \\
\text { Leighton Hospital, Crewe, UK }
\end{array}
$$

\section{References}

1 The NHS Plan: a plan for investment, a plan for reform. London: Stationary Office, 2000. Available online at http://webarchive. nationalarchives.gov.uk/20130107105354/http://www.dh.gov.uk/ prod_consum_dh/groups/dh_digitalassets/@dh/@en/@ps/ documents/digitalasset/dh_118522.pdf [Accessed 9 January 2015].

2 Health and Social Care Information Centre, Academy of Medical Royal Colleges. Standards for the clinical structure and content of patient records. London: HSCIC, 2013. 